\title{
Barrios en guerra. Rio de Janeiro
}

El documental "Barrios en guerra. Río de Janeiro" forma parte de una serie que retrata la problemática del control territorial por bandas armadas en ciudades de Latinoamérica. Fenómeno social arraigado en zonas urbanas con alta exclusión social que presentan elevados niveles de criminalidad asociada al tráfico de drogas u otros ilícitos, lo que genera un soporte de economía criminal.

En este caso particular, se examina la situación de Río de Janeiro previo al desarrollo de la Copa Mundial de Fútbol y de los Juegos Olímpicos, circunstancia que permitió recuperar la presencia estatal en las zonas con asentamiento de bandas criminales.

El documental analiza el entramado social subyacente que soporta a las zonas con limitada presencia del Estado, en las cuales se construyen poderes paralelos que se instauran como autoridades de facto, para el caso de Río de Janeiro, por medio de dos funciones principales que desarrollan las bandas criminales: 1) Ejercicio de control social autoritario, lo que algunos autores denominan dictadura criminal y consiste en el ejercicio del poder para obtener dominación mediante instrumentos coercitivos que persiguen la disuasión y sumisión; 2) Ejercicio de una función social asistencial, que consiste en una especie de populismo criminal sostenido en base a regalías con la población que no está directamente relacionada con la economía criminal. Lo anterior, sin dejar de mencionar que cierta parte de los habitantes en las favelas perciben ingresos del mercado ilícito y esto los convierte en colaboradores de las organizaciones criminales.

Algunas de estas bandas ejercían una especie de control -semi- feudal en ciertas favelas, donde se llegó a sostener que ellas eran el poder real mientras que el Estado ejercía de poder paralelo. Pues las relaciones sociales que allí ocurrían tenían como marco de referencia incorporado las reglas establecidas por las bandas, y no se consideraban las normativas usuales de la sociedad formal.

Este documental resulta ser un recurso valioso para analizar expresiones concretas sobre la presencia de grupos criminales en zonas de exclusión social, donde la combinación entre altos índices de criminalidad más ausencia del Estado, resulta ser una fórmula que produce elevados niveles de inseguridad para la comunidad misma y su entorno. 
Relacionado a lo anterior, emerge la responsabilidad del Estado por recuperar su presencia en estos territorios, lo cual se realizó en Río de Janeiro por medio de la fuerza pública y mediante una combinación de medios coercitivos, disuasivos y preventivos. Cabe destacar que la estrategia diseñada para tal fin supera algunos discursos que aún prevalecen en otras regiones del mundo, donde se huye del uso de la fuerza frente de bandas criminales altamente beligerantes arguyendo posturas de supremacía moral. Para el caso de Río, se consideró que la única manera efectiva de recuperar el control el control territorial era desplazando a dichas bandas con el uso de fuerza pública en incursiones planificadas y avisadas, donde participaron numerosos elementos policiales con el objetivo de ocupar las favelas y permanecer en ellas, incrementando la presencia de policías ahí dentro, sirviendo como inhibidores circunstanciales para la comisión de delitos y afectando la continuidad de sus operaciones básicas.

Algunas comunidades fueron ocupadas sin encontrar resistencia, pero otras sí ofrecieron más problemas y se registraron algunos enfrentamiento armados; no obstante lo anterior, en todas lograron ingresar y posteriormente activaron la segunda etapa del proceso, consistente en introducir policías de proximidad para reconstruir tejido social favorable para el control social legítimo ejercido por la autoridad pública.

Dicha estrategia se plantea como exitosa en el documental, no obstante de presentar algunos problemas relacionados con abusos policiales en el marco de la ocupación de las favelas; sin embargo, este tipo de prácticas no formaron parte de la estrategia en sí misma sino que ocurrieron como resultado inherente al uso de la fuerza y el ejercicio del poder coercitivo.

Algunos expertos consultados advierten que la tendencia podría ser hacia la migración de los grupos delictivos, lo que se conoce como el efecto "cucaracha" o efecto "globo", donde las bandas criminales se desplazan hacia zonas que les puedan ofrecer las condiciones adecuadas para reasentarse.

Finalmente, vale la pena destacar algunas reflexiones de jefes policiales y tomadores de decisión que se expresan en el documental. Afirman que estas estrategias "no acabarán con el problema de drogas en Río, pero sí con los bandidos armados vendiendo drogas"; en el mismo sentido se expresa, que si bien el problema de las drogas no se resuelve 
con ocupaciones de favelas pues en realidad el mercado depende de la existencia de compradores y vendedores, lo que sí es posible lograr es "quebrar el paradigma de los territorios dominados por armas de guerra".

Puede afirmarse que este documental es una buena referencia para jefes policiales, tomadores de decisión en el sector justicia, así como para investigadores que atienden líneas tocantes a la violencia y la política criminal. Se trata de un valioso documento que debe ser revisado para referenciarse de la experiencia brasileña sobre policía comunitaria y recuperación del control territorial por el Estado.

Sinopsis elaborada por Augusto Rigoberto López Ramírez Centro de Investigación Científica Academia Nacional de Seguridad Pública 